\title{
Furanofurone frameworks from disacharides: synthetic studies
}

\section{Luiz Fernando Toneto Novaes, Leandro Vilela de Melo, Lúcia Helena Brito Baptistella}

\author{
Instituto de Química, UNICAMP, PO-Box 6154, 13084-971, Campinas, SP, Brasil
}

*Corresponding author: E-mail: Ihbb@iqm.unicamp.br

Keywords: intramolecular Wittig reactions, disaccharides, furanofurones

\section{INTRODUCTION}

Molecules with furanolactones frameworks have been the target of our synthetic studies for same years. Here we report our recent results related to the use of the abundant and low cost disaccharide lactose for the preparation of new furanofurone compounds. Bicycles like the furanofurone 2 and the furano-pirone $\mathbf{3}$ may present an interesting biological activity, since they have structural similarities with natural products active against human tumor cells ${ }^{1}$. Both 2 and $\mathbf{3}$ present an $\alpha, \beta$-unsaturated carbonyl system, a functional group that, in a general way, may increase some antitumoral properties.<smiles>CC#CCCCOC1OC(O)[C@@H](O)C(O)C1O</smiles><smiles>O=C1C=C2OC(CO)CC(O)C2OC1CO</smiles>

Scheme 1 Formation of the frameworks that are the focus of this work

\section{RESULTS AND DISCUSSION}

For the syntheses of $\mathbf{2}$, it was proposed the preparation of the isosaccharinolactone $\mathbf{4}$ from lactose, followed by a Wittig reaction onto its lactone carbonyl group.<smiles>CC#CC#CCCCOC[C@H]1C[C@@H](O)C(=O)O1</smiles>

Scheme 2. Preparation of the isosaccharinolactone 4

The $\gamma$-lactone 4 was obtained in a reasonable yield of $17 \%$, after a careful and long treatment of the lactose 1 with calcium hydroxide. ${ }^{2}$
This compound may be considered as a chiral building block extremely suitable to our purposes. It possesses two stereogenic centers, one of which being an $\alpha$-carbonyl quaternary carbinol carbon. After a selective protection of the primary hydroxyl groups, compound $\mathbf{5}$ was isolated in $80 \%$ yield. From this tertiary alcohol, the system furenofurone 8 was successfully obtained by using an intramolecular Wittig reaction. The overall yield of $\mathbf{8}$ from 6 was $27 \%$.

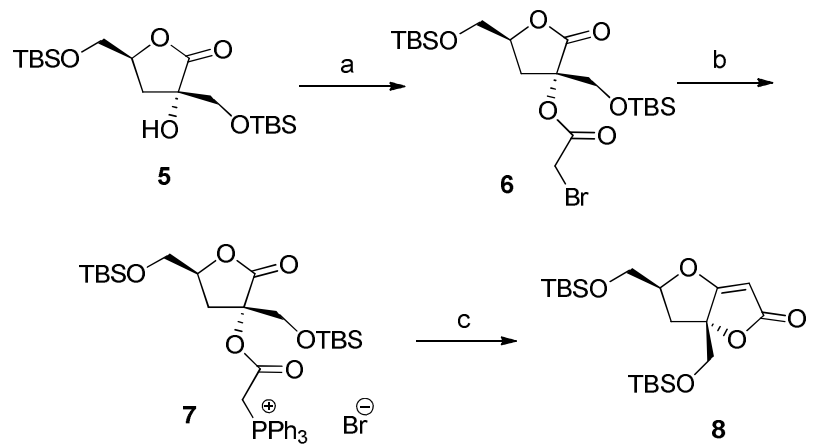

Scheme 3. Preparation of the bicycle 8, a) $\mathrm{BrCH}_{2} \mathrm{COBr}$, $60 \%$, b) $\mathrm{PPh}_{3}$; c) $\mathrm{K}_{2} \mathrm{CO}_{3}, 27 \%$ from 6

\section{CONCLUSION}

Using few steps, it's been possible to synthesize a new furanofurone system from lactose. Deprotection reactions of the hydroxyl groups of $\mathbf{8}$ are in progress for the synthesis of 2.

\section{ACKNOWLEDGEMENTS}

Our acknowledgments to FAPESP

\section{REFERENCES}

1 Fang, X..; Anderson, J. E.; Chang, C.; McLaughlin, J. L. Tetrahedron. 1991, 47, 9751.

2 Whistler, R.L.; BeMiller, J.N. Methods in Carbohydrate Chemistry, vol II, 1963; Academic Press: NY; pp. 477-479 